\title{
BUNDA PAUD MELATI CERIA KELURAHAN PUTAT JAYA KECAMATAN SAWAHAN DAN DEWI SARTIKA KELURAHAN MANUKAN KULON KECAMATAN TANDES SURABAYA
}

\author{
Fransisca R Sunarmi, S.Pd., M.Pd'; Apsari Fajar Prihantini, S. S., M.Pd² and Dr. Mei Indrawati, MM³ \\ ${ }^{1}$ Indonesian Education and Literature Program of STKIP BIM \\ 2 English Education Program of STKIP BIM \\ ${ }^{3}$ Management Faculty of Wijaya Putra University
}

fransisca@stkipbim.ac.id,apsari@stkipbim.ac.id,mei.indrawati.ekonomi@gmail.com

\begin{abstract}
ABSTRAC
Latar belakang PKM ini pada mitra ke 1 ini adalah PPT pos PAUD terpadu Melati Ceria RW 14 kel. Putat Jaya kec. Sawahan, para bundanya 8 orang terdiri dari 3 orang lulusan SMP, 4 orang lulusan SMA dan 1 orang sarjana bukan bidang pendidikan. Tempat pembelajarannya di pendopo makam Tionghoa ditengah-tengah makam Tionghoa, umum dan cina dan tidak memiliki MCK sehingga bila siswa akan buang air besar/kecil menumpang tetangga sekitar. Pada mitra ke 2 ini adalah PAUD Dewi Sartika RW IX Kelurahan Manukan Kulon - Tandes, bertempat di balai RW 09, bunda PAUD berasal dari simpatisan ibu-ibu PKK yang berijazah SMA ada 5 orang, SMK 1 orang dan Sarjana ekonomi 2 orang, terlihat sebagian besar bunda PAUD tidak berkwalifikasi guru. Tujuan PKM ini adalah meningkatkan kualitas bunda PAUD dan menambah sarana prasarana. Metode yang dilaksanakan : Memberi pelatihan dan pendampingan terhadap kepala sekolah dan bunda PAUD dengan mengadakan workshop tentang : a)Perkembangan Anak. b) Pembelajaran Inovatif . c)Pembuatan media (alat peraga). d) pembuatan Silabus dan RPP. c)Mengenalkan model pembelajaran. d)Menambah sarana prasarana. (membuatkan MCK). Hasil PKM:1) Ada media pohon pengetahuan dan panggung boneka 2) Dapat mengajar dengan menggunakan media. 3) Dapat membuat RKH. 4) Sudah ada MCK
\end{abstract}

Kata Kunci : Bunda PAUD, Media, Model Pembelajaran. 


\section{PENDAHULUAN}

Pendidikan Anak Usia Dini (PAUD) adalah pendidikan anak di usia baru lahir hingga usia 6 tahun, dalam pengabdian masyarakat ini yang ditujukan ke PAUD Dewi Sartika dan Melati ceria dengan usia 3 sampai dengan 4 tahun. Maka disini dijelaskan analisis situasi yang menjadi mitra 1 dan 2 dalam Program Kemitraan Masyarakat (PKM) ini. Kami Tim PKM tertarik mengadakan PKM pada bunda PAUD dikarenakan adanya analisis situasi sbb :

Situasi Mitra 1: Pada mitra ke 1 ini adalah PPT pos PAUD terpadu Melati Ceria RW 14 kel. Putat Jaya kec. Sawahan, yang tempat belajarnya ada di Pendopo makam Tionghoa, pendopo itu ada disekitar makammakam diantaranya makam Islam, makam Tionghoa, makam orang kampung, tempatnya sangat kumuh sekali dan pendopo tersebut terbuat dari papan yang sudah tua. PAUD Melati Ceria berdiri sdh 6 tahun yang lalu sekarang sudah memiliki 100 siswa anak usia dini dengan para bundanya 8 orang terdiri dari 3 orang lulusan SMP, 4 orang lulusan SMA dan 1 orang sarjana. Melihat latar belakang pendidikan bunda PAUD tersebut perlu penambahan pengetahuan tentang perkembangan anak, pengelolaan manajemen sekolah, pembelajaran dan perangkatnya. Berdasarkan surve PAUD tersebut belum mempunyai media pembelajaran yang tepat, yang mereka miliki hanya balok-balok, itupun sumbangan dari dispendik, yang mana bunda PAUDnya belum bisa menerapkan media itu. Menurut pakar kePAUDan media itu juga belum memadai dalam perkembangan pendidikan di anak usia dini. Perlu dibutuhkan permainan sentra untuk merangsang kreatifitas siswa. Permainan sentra itu antara lain sentra alam, sentra seni, sentra kesehatan dan sentra keluarga, selain itu pendopo yang sebagai tempat pembelajaran itu tidak mempunyai MCK sehingga para siswa bila akan buang air kecil harus lari ke tetangga sekitar.
Berdasarkan surve yang dilakukan perlu penambahan pengetahuan tentang perkembangan anak usia dini, pengelolaan manajemen sekolah, kegiatan belajar mengajar dan pengimplementasikan model dan media pembelajaran terhadap Kepala sekolah bunda PAUD.

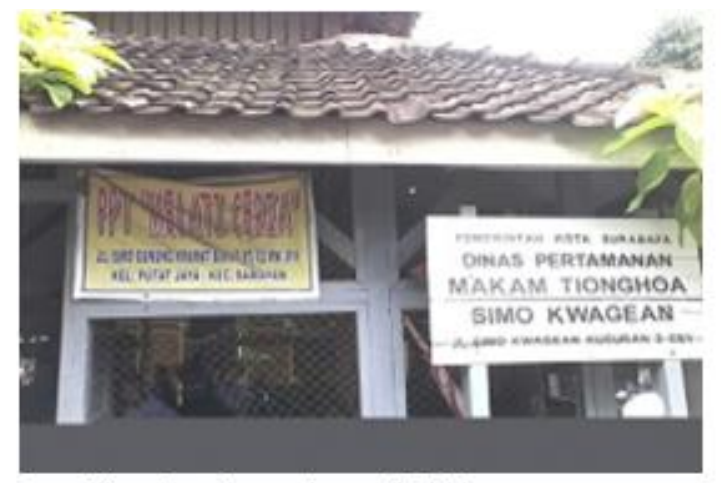

Gbr. 1. Tempat pembelajaran

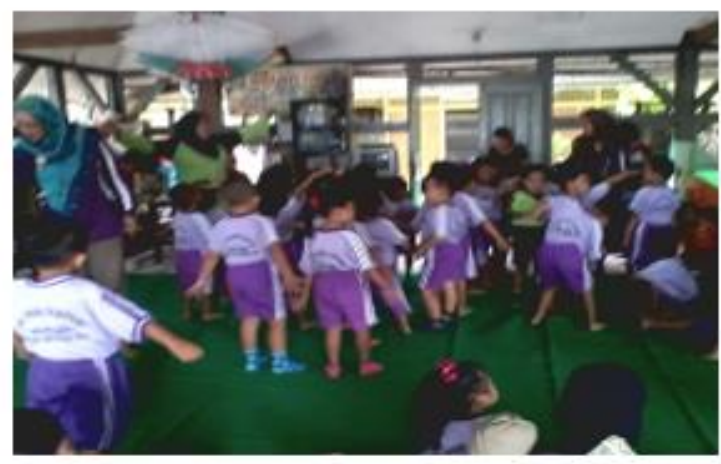

Gbr. 2. Proses belajar mengajar yang belum terarah.

Mitra 2 : Pada mitra ke 2 ini adalah PAUD Dewi Sartika RW IX Kelurahan Manukan Kulon - Tandes, bertempat di balai RW siswa berjumlah 57 anak, bunda PAUD berasal dari simpatisan ibu-ibu PKK yang berijazah SMA ada 5 orang, SMK 1 orang dan Sarjana ekonomi 2 orang, karena bunda PAUD tidak berkwalifikasi guru maka masih sangat kurang pengetahuan tentang pendidikan keguruan dan pendidikan kePAUDan sehingga belum menguasai tehnik pengajaran seperti penerapan model-model pembelajaran, cara mengajarnya tidak sesuai dengan pendidikan di PAUD, cara 
pengaturan meja kursi belajar tidak menunjukan pembelajaran di PAUD yang menyenangkan, pembelajaran tegang dan media yang digunakan sebatas pengalaman bunda PAUD sewaktu anaknya dulu bersekolah di Taman kanak-kanak, dengan jumlah siswa tersebut diatas kursi dan meja yang dimiliki 35 pasang maka tempat duduk belum memadai, dengan demikian pembelajaran dijadikan 2 kali pertemuan, pagi jam 08.00 - 10.00 dan 10.00 - 12.00. dilaksanakan setiap hari Senin, Rabu dan Sabtu.

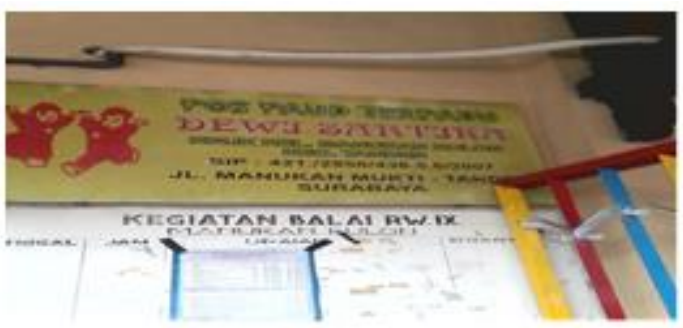

Grr. 4. Tempat belajar

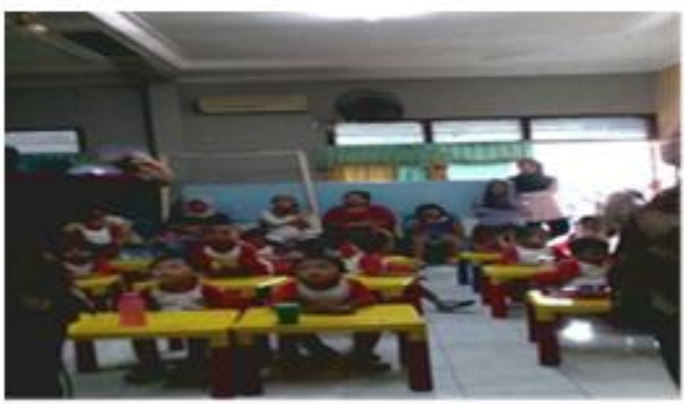

Gbr. 5. Proses belajar mengajar yang tidak sesuai dengan pendidikan di PAUD

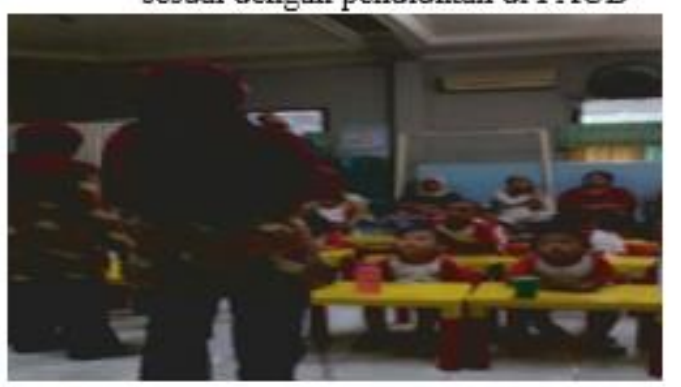

Gbr. 6. Sarana bermain

\section{Permasalahan Mitra}

Berdasarkan analisis situasi pada Mitra ke 1 PAUD Melati Ceria masalah yang dihadapi sangat berpengaruh terhadap pendidikan anak usia dini, dengan kurangnya pengetahuan tentang perkembangan anak maka bunda PAUD dalam melaksanakan pembelajarannya tidak maksimal karena latar belakang bunda PAUD hanyalah lulusan SMP ada 3 orang, SMA ada 4 orang dan 1 orang sarjana. Daerah sekitar Putat Jaya tempat PAUD tersebut banyak keluarga muda yang mempunyai anak kecil. Maka dengan jumlah siswa 100 anak perlu penambahan pengetahuan pengelolaan kelas, pembelajaran inovatif

Dalam team ini ketua mempunyai pengalaman mengajar di TK selama 6 tahun dan di SD 24 tahun sehingga dalam mengimplementasikan Teknologi Pendidikan sangat paham sekali serta mengajar di Pendidikan Guru PAUD (PGPAUD), membimbing PPL mahasiswa PAUD di TK Joins School. Anggota 1 Ibu Apsari juga mempunyai tugas mengajar di Pendidikan Guru PAUD Psikologi Pendidikan, Anggota 2 Ibu Mei mempunyai tugas sebagai Team Penjaminan Mutu di Universitas Wijaya Putra. Mahasiswa yang terlibat adalah 2 orang dari Prodi PAUD dan 1 orang mahasiswa dari Prodi Bahasa dan Sastra Indonesia.

\section{Solusi Pemecahan Masalah}

Pembelajaran di PAUD sangat diperlukan keterampilan belajar mengajar yang khusus yang proses pembelajarannya disesuaikan dengan kondisi siswa, model pembelajaran harus inovatif sehingga membuat pembelajaran di kelas menyenangkan. Kondisi PAUD yang menjadi objek pengabdian, cara belajar yang disampaikan para bundanya tidak memperhatikan pendidikan anak usia dini seperti : banyak mengunakan ceramah, posisi duduk monoton, gaya bahasa dalam bertutur kata kurang bagus. Maka perlunya pembinaan bagi bunda PAUD.

\section{METODE PELAKSANAAN}

Pendidikan 
Berdasarkan target dan luaran yang ada, pelaksanaan kegiatan PKM ini dalam menjawab permasalahan yang ada perlu pelaksanaan solusi dengan menentukan metode dan beberapa langkahlangkah kegiatan.

Dalam penerapan Program Kemitraan Masyarakat bagi Kepala Sekolah dan bunda PAUD Melati Ceria kelurahan Putat Jaya kecamatan Sawahan dan Dewi Sartika kelurahan Manukan Kulon kecamatan Tandes Surabaya sebagai mitra dikarenakan persoalan yang ada yang sudah diuraikan pada permasalahan. Dengan latar belakang para bunda PAUD yang tidak mempunyai ijazah berkualifikasi pendidikan. Hanya pada kepala sekolah Melati Ceria yang su dah sarjana, para bundanya hanya ibu-ibu PKK yang lulusan SMP, SMK dan SMA, itu terdapat di bunda PAUD Melati ceria maupun Dewi Sartika. Permasalahan ke 2 mitra tersebut hampir sama yaitu dibutuhkan profesional guru yang mempunyai wawasan luas dalam kePAUDan.

Metode yang akan digunakan dengan memberikan workshop dan pelatihan serta pendampingan secara intensif kepada kepala sekolah dan bunda-bunda PAUD ke Mitra tersebut berjumlah 18 orang, supaya dengan adanya workshop dan pelatihan serta pendampingan secara intensif dapat memberikan motivasi dalam kegiatan profesional guru serta peningkatan keterampilan pedagogik dan manajerial.

Agar lebih jelas dalam pelaksanaan workshop, pelatihan dan pendampingan perlu dibuatnya langkah-langkah kegiatan agar dalam pelaksanaan PKM nanti tepat pada sasaran, adapun langkah-langkah tersebut sebagai berikut :

1. Workshop dengan tema "Pembelajaran Inovatif Pada Anak Usia Dini” selama 3 hari.

a. Hari ke 1: Diberikan pengetahuan tentang Perkembangan Anak dan teori pembelajaran inovatif, modelmodel, media pembelajaran pada anak usia dini, cara-cara membuat Silabus dan RKH. b. Hari ke 2 : Pelatihan membuat silabus dan RKH dan membuat media.

c. Hari ke 3 : Pendampingan praktek mengajar sesuai RKH yang dibuat.

Mitra 1 dan 2 berpartisipasi dalam pelaksanaan program ini, antara lain :

1. Bersedia sebagai tempat pengabdian

2. Bersedia mengikuti workshop

3. Membantu menyiapkan tempat untuk workshop karena workshop bertempat di balai RW 09 Kelurahan Manukan Kulon

4. Membantu minta ijin ke bapak RW

5. Membantu menyiapkan sarana prasarana

Dalam program kemitraan masyarakat ini menjadi komitmen dari TIM PKM dengan PAUD Melati Ceria dan Dewi Sartika, karena peran yang ditawarkan dalam melakukan pelatihan dan pendampingan secara berkelanjutan baik secara akademik maupun teknis akan menghasilkan proses belajar dan mengajar yang optimal sehingga membuat anak-anak usia dini yang mandiri.

\section{PEMBAHASAN DAN HASIL}

Berdasarkan permasalahan yang ada pada Mitra 1(Melati Ceria) dan 2 (Dewi Sartika) maka yang dilakukan oleh tim untuk menjawab permasalah yang ada adalah :

1. Mengadakan pertemuan untuk membahas sosialisasi ke Mitra 1 dan 2.

2. Mengadakan sosialisasi ke Mitra 1 dan 2.

3. Menyusun rencana dan mempersiapkan pelaksanaan Workshop.

4. Melaksanakan workshop : "Inovasi Pembelajaran"

5. Melaksanakan pelatihan bernyanyi dan bermusik.

6. Pendampingan pembuatan $\mathrm{RKH}$.

7. Pendampingan membuat media.

8. Peninjauan pembuatan MCK.

9. Melaksanakan pembelajaran diluar kelas outbond di alas prambon.

$$
\text { Pendidikan }
$$


Adapun pelaksanaannya adalah sbb:

1. Pada tanggal 22 Januari 2018 bersama mahasiswa yang terlibat dalam PKM ini, mengadakan pertemuan untuk membahas sosialisasi ke Mitra 1 dan 2.

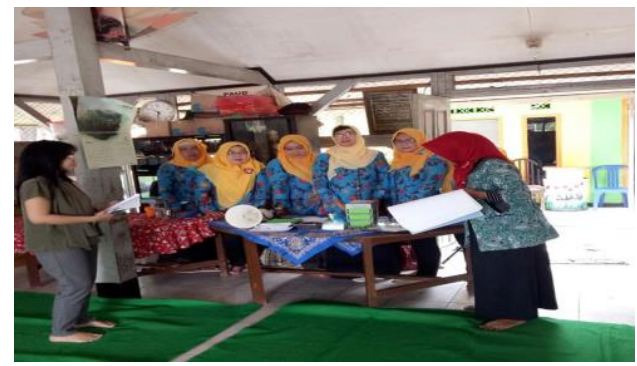

Gbr.7. Pertemuan

2. Pada tanggal 10 Maret 2018 mengadakan sosialisasi ke Mitra 1 dan 2

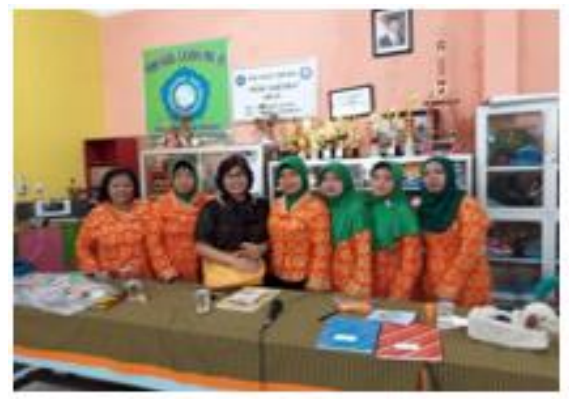

Gbr. 8. Sosialisasi

3. Pada tanggal 4 April 2018 menyusun rencana dan mempersiapkan pelaksanaan Workshop.

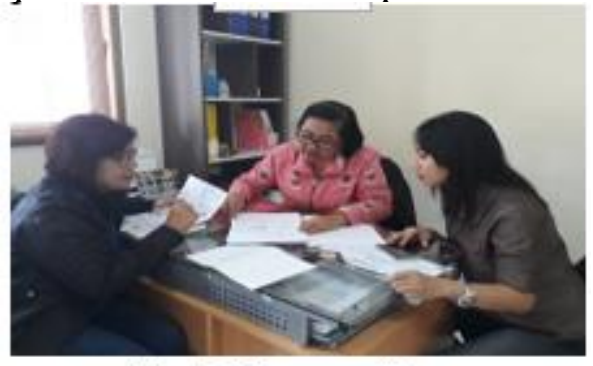

Gbr. 9. Menyusun Rencana

4. Pada tanggal $10 \mathrm{sd} 12 \mathrm{Mei}$ pelaksanaan workshop : "Inovasi Pembelajaran"
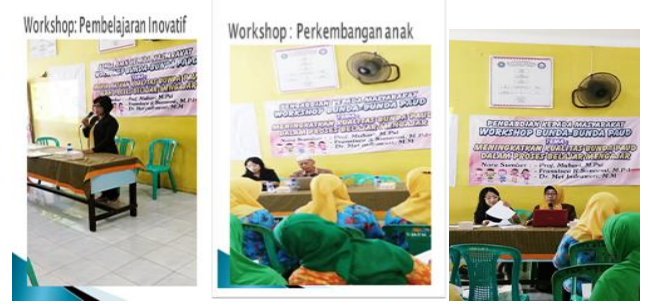

Gbr. 10. Workshop

5. Pada tanggal 14 sd 16 Mei 2018 melaksanakan pelatihan bernyanyi dan bermusik

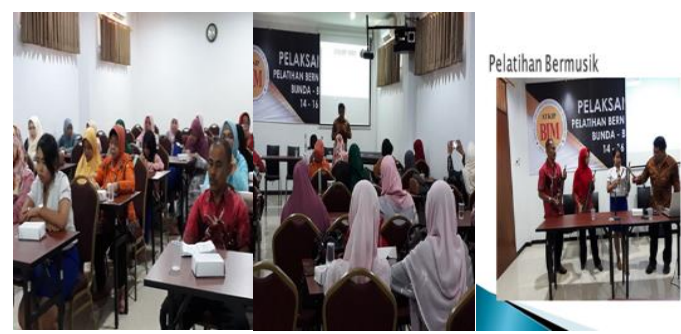

Gbr.11. Pelatihan Bernyanyi dan Bermusik

6. Pada bulan Juni, Juli dan Agustus 2018 (1 Minggu 1 kali) pendampingan pembuatan RKH

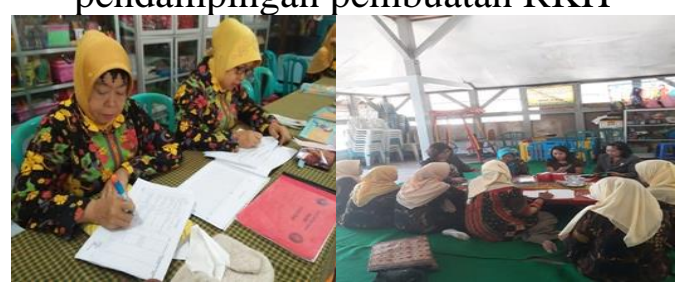

Gbr. 12. Pembuatan RKH

7. Pada 28 Juni 2018 pendampingan membuat media

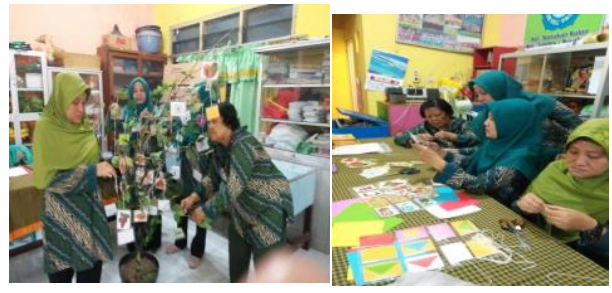

Gbr. 13. Pembuatan Media

8. Pada tanggal 1 Juli 2018 peninjauan pembuatan MCK 


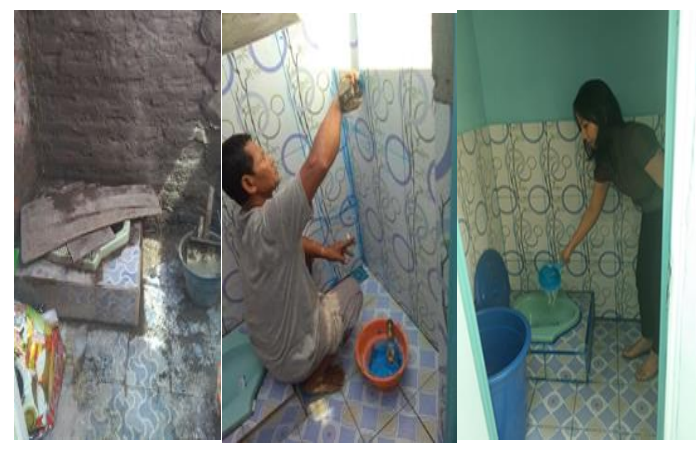

Gbr. 14. Pembuatan MCK

9. Pada tanggal 28 April 2018 pelaksanaan pembelajaran diluar kelas outbond di alas prambon.

4. PEMBELAJARAN DI LUAR KELAS

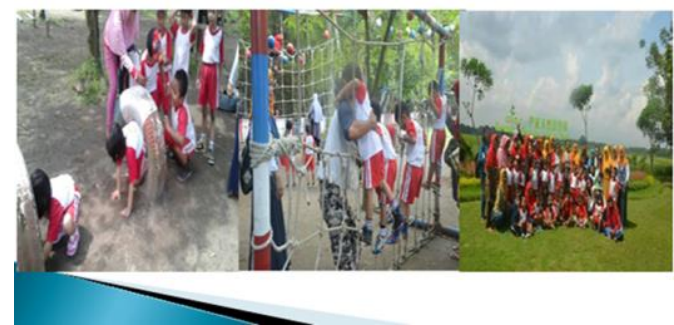

Gbr. 15. Pembelajaran di Luar Kelas

\section{KESIMPULAN}

\section{A. Kesimpulan}

Pembelajaran inovatif sangat diperlukan oleh bunda PAUD Melati Ceria dan Dewi Sartika sebagai peningkatan proses belajar mengajar karena para bunda PAUD tidak berkualifikasi pendidikan. Peningkatan itu melalui workshop dengan tema : peningkatan pembelajaran inovatif bunda PAUD dalam proses belajar mengajar, materi yang disampaikan adalah perkembangan anak usia dini, pembelajaran inovatif, membuat $\mathrm{RKH}$ dan pendampingan penerapan RKH sesuai media yang dibuatnya. Setelah bunda PAUD menerapkan ilmu yang sudah diterima pada kegiatan pelaksanaan PKM, pembelajaran inovatif bunda PAUD ada peningkatan dengan hasil sangat memuaskan. Dengan peningkatan pembelajaran inovatif hasil pemerolehan peserta didik meningkat dari $2 \leq$ Rata-rata $<3=$ kurang memuaskan menjadi $4 \leq$ Rata-rata $<5=$ sangat memuaskan artinya peserta didik sudah dapat mengikuti pembelajaran secara terarah.(Rubrik Penilaian terlampir)

Yang menjadi kendala dalam upaya meningkatkan pembelajaran inovatif tersebut yaitu kurangnya kesadaran para bunda PAUD untuk menambah pengetahuan seperti datang workshop, pelatihan, pembuatan $\mathrm{RKH}$, membuat media, untuk supaya kegiatan itu bisa berhasil harus diberikan motivasi terlebih dahulu dan pemberian reward bagi yang nilainya tinggi dari hasil observasi aktifitas bunda PAUD. Dalam pengolahan data menggunakan instrumen penilaian aktifitas guru dan siswa kelebihannya untuk mengukur kemampuan guru dalam pembelajaran inovatif secara empiris. Penilaian aktifitas guru dan siswa merupakan keterkaitan hasil perolehan terakhir. Bila rata-rata peserta didik baik maka secara otomatis penilaian aktifitas guru baik pula.

\section{B. Saran}

Saran yang diberikan untuk para guru pada umumnya yaitu guru harus selalu upgrade ilmu pengetahuannya dalam pengelolaan kelas dengan pembelajaran inovatif, menyusun perangkat pembelajaran dan selalu memanfaatkan media dalam proses belajar mengajar.

Penelitian ini adalah hasil dari Program Kemitraan Masyarakat yang didukung oleh Hibah DIKTI.

\section{UCAPAN TERIMAKASIH .}

Ucapan terimakasih disampaikan kepada PUSLIT STKIP Bina Insan Mandiri Surabaya yang telah memberikan kontribusi dan kesempatan dalam melaksanakan Program Kemitraan Masyarakat. Terima kasih pula kepada KEMENRISTEK DIKTI yang telah memberikan dukungan berupa hibah Program Kemitraan Masyarakat pada tahun 2018.

\section{REFERENSI}

Dikti, 2017. Panduan Pelaksanaan Penelitian Dan Pengabdian Kepada Masyarakat Di Perguruan Tinggi 
Edisi XI. Surabaya. 2017.

Elizabeth Harloek, 1993. Perkembangan Anak. Jakarta. Erlangga.

Musfiqoon, 2012. Pengembangan media \& Sumber Pembelajaran. Jakarta, PT. Prestasi Pustakaraya.

Putra Yosa, 2007. Kalimat Efektif. Bandung. Refika Aditama.

Sudjana Nana, 2009. Rivai Ahmad, Teknologi Pengajaran. Bandung, Sinar Baru Algensindo.

Wulan Sri, 2013. Modul Media Pengembangan Bahasa Anak Usia Dini. Surabaya.

Muhari. 2016. Kumpulan Makalah Perkembangan Anak. UNESA Surabaya
Suryono Yoyon dkk, 2015. Pengembangan Model-model Pembelajaran untuk Peningkatan Kualitas Pendidikan Anak Usia Dini, LPPM. UNY

Lasaiba, Djatmila. 2016. Pola Pengembangan Model Pembelajaran Pendidikan Anak Usia Dini di lingkar kampus IAIN Ambon. ( Jurnal Fiktratuna volume 8 Nomor 2, 2016. Hal. 79)

Eliza, Delfi. 2013. Penerapan Model Pembelajaran Kontekstual Learning(CTL) Berbasis Centra Di Taman Kanak-kanak. (Pedagogik. Jurnal ilmiah ilmu pendidikan

http://ejournal.unp.ac.id/index.php/pedagogik) 